\title{
Study the Behavior of Reinforced Concrete Beam Using Finite Element Analysis
}

\author{
Abdulsamee Halahla \\ Fahad Bin Sultan University \\ P.O Box 15700, Tabuk, Saudi Arabia \\ ahalahla@fbsu.edu.sa
}

\begin{abstract}
Several methods have been utilized to study the response of concrete structural components. Experimental based testing has been widely used as a means to analyze individual elements and the effects of concrete strength under loading. The use of finite element analysis to study these components has also been used. Concrete structural components such as beams, columns, walls exist in various buildings and bridges. Understanding the response of these components of structures during loading is crucial for the development of an efficient and safe structure. Recently Finite Element Analysis (FEA) is also used to analyze these structural components. Finite element software [1], is used for modeling and analysis by conducting non- linear static analysis. This paper is a study of reinforced concrete beam using finite element analysis to understand their load-deflection response. A reinforced concrete beam model is studied and compared to experimental data. Characteristic points on the load-deformation response curve predicted using finite element analysis were compared to theoretical (hand-calculated) results. Conclusions were then made as to the accuracy of using finite element modeling for analysis of concrete. The results compared well to experimental and hand calculated.
\end{abstract}

Keywords: Concrete, Load deflection, Crack, Material nonlinearity, Finite element analysis.

\section{Introduction}

Concrete structural components exist in buildings and bridges in different forms. Understanding the response of these components during loading is crucial to the development of an overall efficient and safe structure. Different methods have been utilized to study the response of structural components. Experimental based testing has been widely used as a means to analyze individual elements and the effects of concrete strength under loading. While this is a method that produces real life response, it is extremely time consuming, and the use of materials can be quite costly. The use of finite element analysis to study these components has also been used. Unfortunately, early attempts to accomplish this were also very time consuming and infeasible using existing software and hardware. In recent years, however, the use of finite element analysis has increased due to progressing knowledge and capabilities of computer software and hardware. It has now become the choice method to analyze concrete structural components. The use of computer software to model these elements is much faster, and extremely cost-effective. To fully understand the capabilities of finite element computer software, one must look back to experimental data and simple analysis. Data obtained from a finite element analysis package is not useful unless the necessary steps are taken to understand what is happening within the model that is created using the software. Also, executing the necessary checks along the way is key to make sure that what is being output by the computer software is valid. By understanding the use of finite element packages, more efficient and better analyses can be made to fully understand the response of individual structural components and their contribution to a structure as a whole. This paper is a study of reinforced concrete beams using finite element analysis to understand the response of reinforced concrete beams due to transverse loading. The objective of this Study is to investigate and evaluate the use of the finite element method for the analysis of reinforced concrete beam. A mild-steel reinforced concrete beam with flexural and shear reinforcement was analyzed to failure and compared to experimental results. A calibration model using a commercial finite element analysis package (ANSYS) was set up and evaluated using experimental data. A mild-steel reinforced concrete beam with flexural and shear reinforcement was analyzed to failure and compared to experimental results to calibrate the parameters in ANSYS for later analyses. 


\section{Literature Review}

The use of FEA has been the preferred method to study the behavior of concrete (for economic reasons). [2] Contains a collection of papers concerning finite element analysis of reinforced concrete structures. This collection contains areas of study such as: seismic behavior of structures, cyclic loading of reinforced concrete columns, shear failure of reinforced concrete beams, and concrete steel bond models. [3] Also put together a collection of papers dealing with inelastic behavior of reinforced concrete structures under seismic loads. The monograph contains contributions that outline applications of the finite element method for studying post-peak cyclic behavior and ductility of reinforced concrete columns, the analysis of reinforced concrete components in bridge seismic design, the analysis of reinforced concrete beam-column bridge connections, and the modeling of the shear behavior of reinforced concrete bridge structures. [4] Study Analytical modeling of post-tensioned precast beam-to-column connections, Finite element analysis software, ANSYS, is used to simulate 3D nonlinear finite element model for both precast and cast-in-place beam-to-column connection under the effect of cyclic load to investigate the connection strength, behavior and stiffness. The elasticperfectly plastic model of the mild and pre-stressed steel and the link8 element was considered, while for the concrete material the Hognestad model was used and considering multi-linear isotropic material, in addition William-Warnke failure model was used and solid65 element with eight node considered for the concrete and reinforced concrete since this element have the property of crack under tension, creep, crushing under compression and plastic deformation, the smeared crack model was selected to define the cracked concrete, moreover for the place of end support and the place of the applied load the solid45 element was used to prevent the crushing of concrete. The figure below show the element type used in finite element model [5] A Finite element analysis software, ANSYS, and, SAP2000, are used to investigate the benefit of strengthening beam-column joint of ordinary RC frame by FRP sheets by CFRP web-bonding of joint in order to improve the seismic performance and behavior factor R. the model take into account the geometric nonlinearities and the material inelasticity, for concrete material William-Warnke failure model was used, and solid65 element with eight node considered for the concrete, while the FRP considered as anisotropic material as well as bilinear material, and solid45 element with 8-nodes was used, in addition link8 element was used for steel bar. The nonlinear static pushover analysis carried out using SAP2000 finite element software, under the effect of lateral load, nonlinear link element was used in order to consider the additional stiffness provided by web-bond FRP sheet. [6]A Finite element analysis software, ANSYS, is used to simulate beam-column joint retrofitted with carbon fiber reinforced polymer sheets which was subjected to statics load at the cantilever beam, to study the performance of the CFRP in retrofitting the beam-column two model was carried, first one without the CFRP and the second one with CFRP wrapped at the beam-column joint, the both end of the column considered as hinge and the static load applied at the end of the beam. The concert materials represented by solid65 element and link8 element were used for reinforced concrete while for the warp CFRP the solid 45 element was used. [7] Finite element analysis software, ANSYS (ANSYSWORKBENCH), is used to investigate the fire performance of CFRPstrengthened member and their resistance to heat transfer, the study done for RC T-beam exposed to ASTM E119 standard fire, since of symmetry only the quarter of the beam was modeled. The elastic-perfectly plastic with hardening model for the steel (bilinear stress-strain curve), while for the concrete material the standard nonlinear constitutive model based on William-Warnke model was used. Due to the transient thermal analysis the thermal element solid70 with 3D eight nodes was used for the concrete and thermal element link33 with 3D uniaxial 2-node conduction) was used for reinforced steel bar, these thermal element were converted to structural element as the following; i) for the concrete material thermal element solid70 to structural element solid 65 ii) for FRP thermal element solid70 to structural element solid46 iii) for steel thermal element solid33 to structural element link8.

\section{Finite Element Analysis}

Experimental analysis is widely carried out to study individual component members and the concrete strength under various loading conditions. This method provides the actual behavior of the structure. But it is time consuming and expensive. Finite element analysis is also used to analyze these structural components. Finite Element Analysis (FEA) is a

method used for the evaluation of structures, providing an accurate prediction of the component's response subjected to various structural loads. The use of FEA has been the preferred method to study the behavior of concrete as it is much 
faster than the experimental method and is cost effective. With the invention of sophisticated numerical tools for analysis like the finite element method (FEM), it has become possible to model the complex behavior of reinforced concrete beams using Finite Element modeling.

\subsection{Geometry of the Beam}

The geometry of the full size beam is shown in Figure 1. The span between the two supports is 15 feets. Beam is simply supported by providing roller support on both the sides. Two point loads are applied at the midspan of the beam.. The details of the RC beam are as shown in Figure2.

\subsection{Material Property}

Modeling an element for the behavior of concrete is a challenging task. Concrete is a brittle material and has exhibit different behavior in compression and tension, the concrete Material is consider as linear isotropic and multi-linear isotropic material properties to properly model concrete, for steel Reinforcement Material is consider as linear isotropic and bilinear isotropic material, while for the Steel Plate a Linear isotropic. The ANSYS program requires the uniaxial stress-strain relationship for concrete in Compression. The Solid65 element requires linear isotropic and multi-linear isotropic material properties to properly model concrete. The multi-linear isotropic material uses the Von-Misses failure criterion a long with [8] model to define the failure of the concrete. Simplified stress strain relationship for concrete in compression is obtained and is shown in Fig 3. Parameters needed to define the material models can be found in Table 1. As seen in Table 1, there are multiple parts of the material model for each element. The element types for this model are shown in Table 1. The Solid65 element was used to model the concrete. This element has eight nodes with three degrees of freedom at each node - translations in the nodal $\mathrm{x}, \mathrm{y}$, and $\mathrm{z}$ directions. This element is capable of plastic deformation, cracking in three orthogonal directions, and crushing. Solid45 element was used for steel plates at the supports for the beam. This element has eight nodes with three degrees of freedom at each node - translations in the nodal $\mathrm{x}, \mathrm{y}$, and $\mathrm{z}$ directions. A Link8 element was used to model steel reinforcement. This element is a 3D spar element and it has two nodes with three degrees of freedom - translations in the nodal $\mathrm{x}, \mathrm{y}$, and $\mathrm{z}$ directions. This element is also capable of plastic deformation.

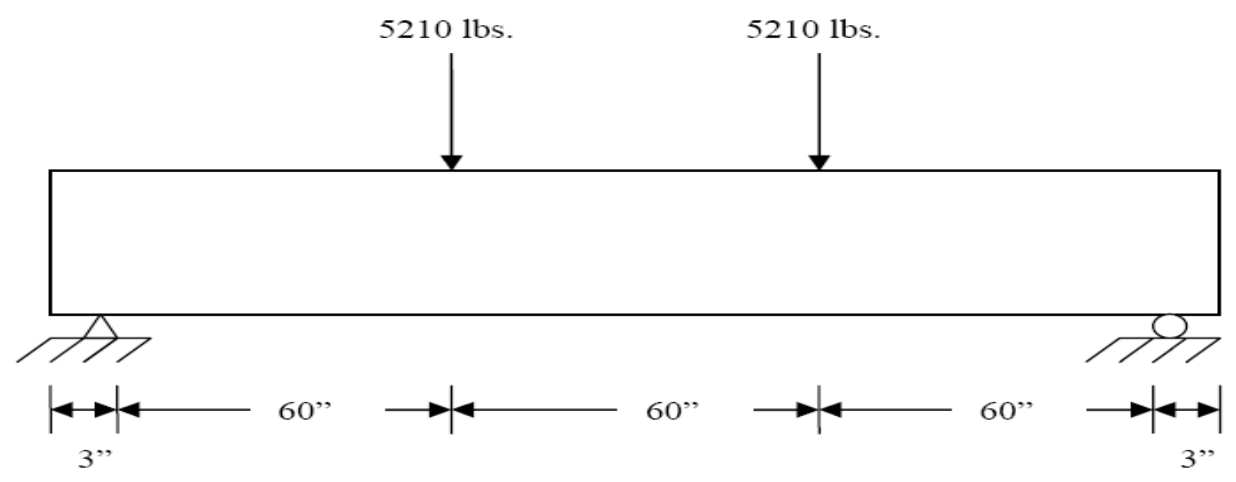

Fig. 1: Geometry of the control Beam. 


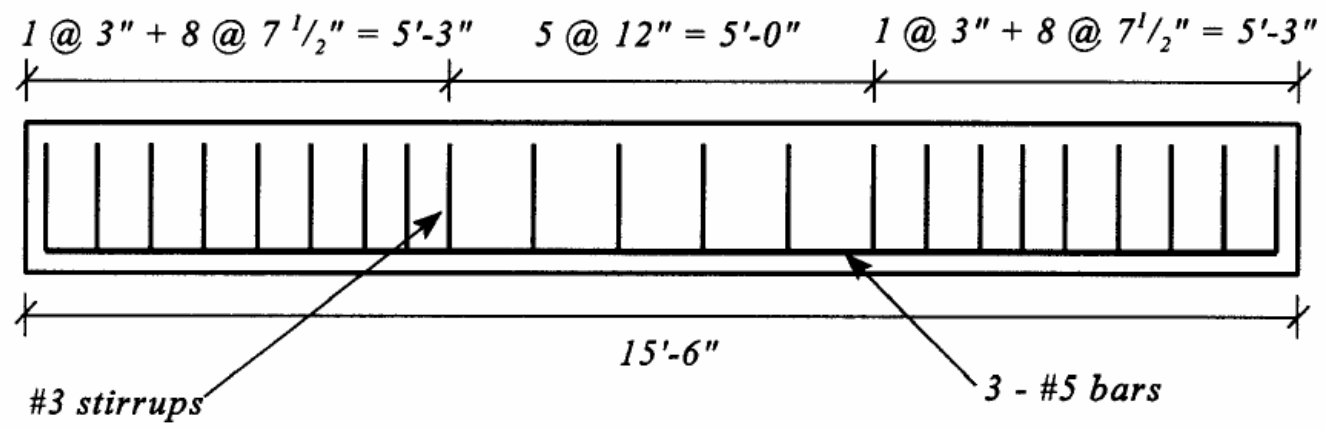

Fig. 2: Typical Details for Control Beam Reinforcement.

Table 1: Material Model and Element Types for Working Model.

\begin{tabular}{|c|c|c|c|}
\hline Material & Element Type & \multicolumn{2}{|c|}{ Material Properties } \\
\hline Concrete & Solid 65 & \multicolumn{2}{|c|}{ Linear Isotropic } \\
\hline & & $\mathrm{E}$ & 3949076 Psi \\
\hline & & $\mathrm{v}$ & 0.3 \\
\hline & & \multicolumn{2}{|c|}{ Multi-linear Isotropic } \\
\hline & & Strain & Stress Psi \\
\hline & & 0.00036 & 1421.7 \\
\hline & & 0.0006 & 2233 \\
\hline & & 0.0013 & 3991 \\
\hline & & 0.0019 & 4656 \\
\hline & & 0.00243 & 4800 \\
\hline \multirow{6}{*}{$\begin{array}{c}\text { Steel } \\
\text { Reinforcement }\end{array}$} & Link 8 & \multicolumn{2}{|c|}{ Linear Isotropic } \\
\hline & & $\mathrm{E}$ & 29000000 Psi \\
\hline & & $\mathrm{v}$ & 0.3 \\
\hline & & \multicolumn{2}{|c|}{ Bilinear Isotropic } \\
\hline & & Yield Stress & 60000 Psi \\
\hline & & Tangential Modulus & 2900 Psi \\
\hline Steel Plate & Solid 45 & \multicolumn{2}{|c|}{$\begin{array}{c}\text { Linear Isotropic } \\
\end{array}$} \\
\hline & & $\mathrm{E}$ & 29000000 Psi \\
\hline & & $\mathrm{v}$ & 0.3 \\
\hline
\end{tabular}




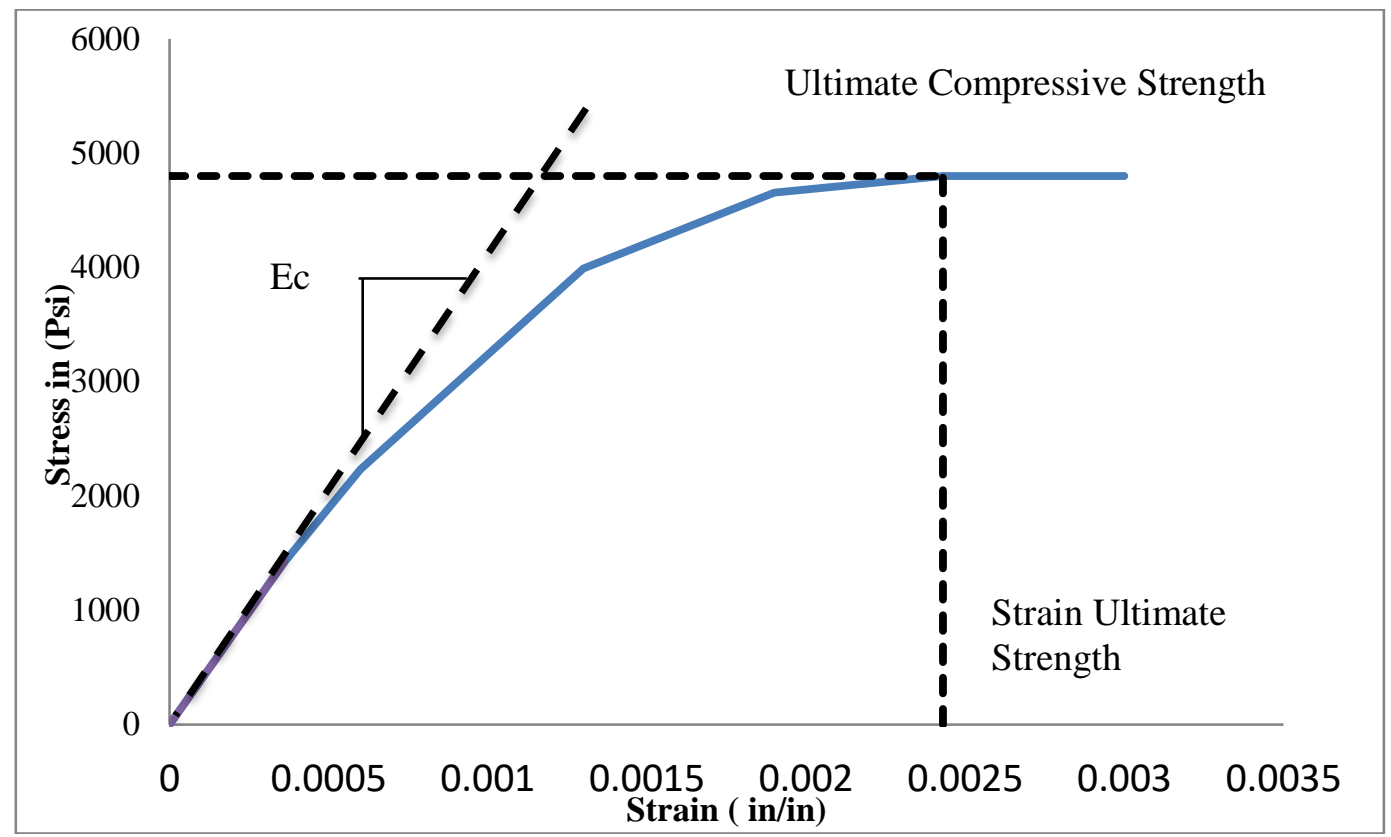

Fig. 3: Uniaxial Stresses-Strain Curve for Concrete.

\subsection{Finite Element Modeling}

Due to symmetry, only quarter of the beam were model in order to save the computation time. The support is a 3 in. $x$ 5 in. $x 1$ in. steel plate, while the plate at the load point is 6 in. $x 5$ in. $x 1$ in. The combined volumes of the plate, support, and beam are shown in Figure 4. The FE mesh for the beam model is shown in Figure 5. To obtain good results from the Solid65 element, the use of a rectangular mesh is recommended. Therefore, the mesh was set up such that square or rectangular elements were created (Figure 5). The volume sweep command was used to mesh the steel plate and support. This properly sets the width and length of elements in the plates to be consistent with the elements and nodes in the concrete portions of the model. The overall mesh of the concrete, plate, and support volumes is shown in Figure 5. The necessary element divisions are noted. The meshing of the reinforcement is a special case compared to the volumes. However, the necessary mesh attributes as described above need to be set before each section of the reinforcement is created.

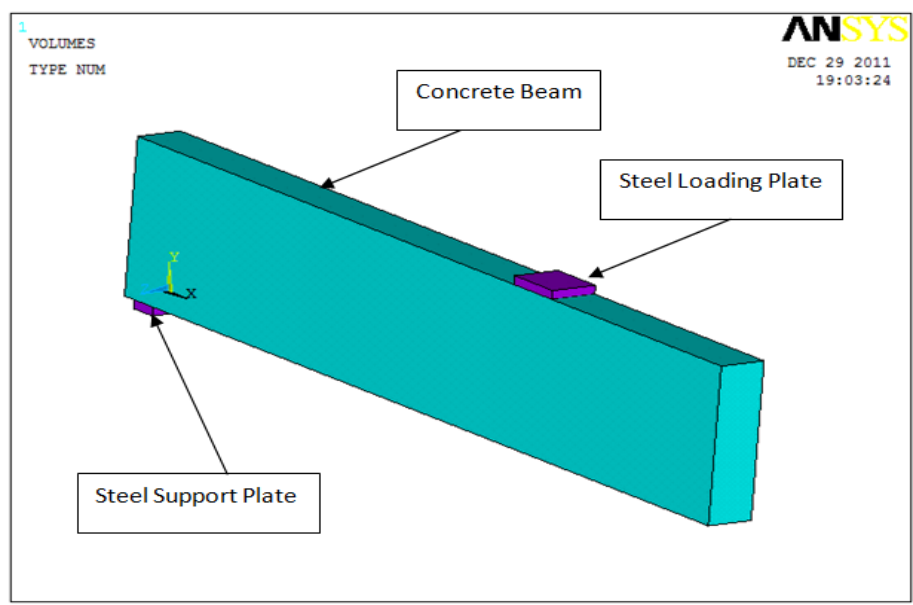

Fig. 4: Volumes Created in ANSYS. 


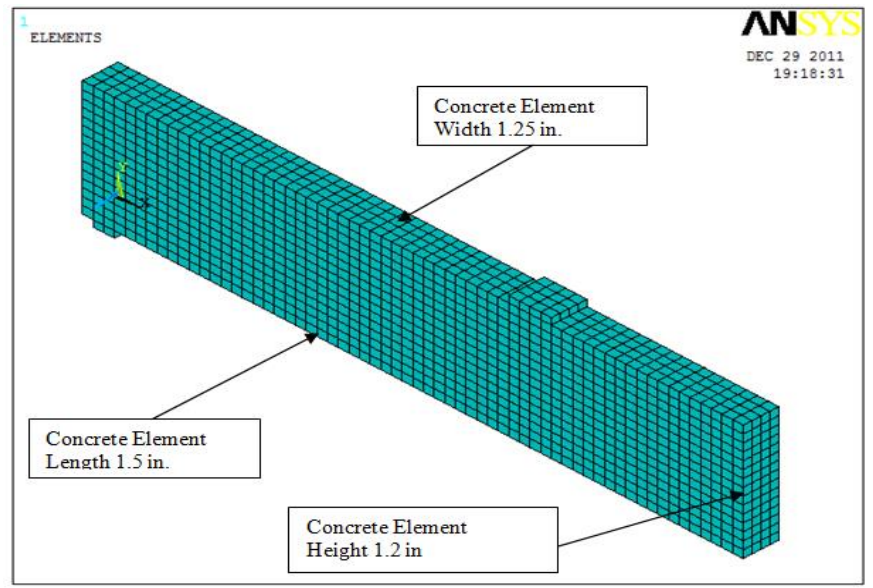

Fig. 5: Meshes of the Concrete, Steel Plate, and Steel Support.

Displacement boundary conditions are needed to constrain the model to get a unique solution. To ensure that the model acts the same way as the experimental beam, boundary conditions need to be applied at points of symmetry, and where the supports and loadings exist. The symmetry boundary conditions were set first. The model being used is symmetric about two planes. Nodes defining a vertical plane through the beam cross-section centroid define a plane of symmetry. To model the symmetry, nodes on this plane must be constrained in the perpendicular direction. These nodes, therefore, have a degree of freedom constraint $U X=0$. Second, all nodes selected at $Z=0$ define another plane of symmetry. These nodes were given the constraint $\mathrm{UZ}=0$. The support was modeled in such a way that a roller was created. A single line of nodes on the plate were given constraint in the UY, and UZ directions, applied as constant values of 0 . By doing this, the beam will be allowed to rotate at the support.The force, $\mathrm{P}$, applied at the steel plate is applied across the entire centerline of the plate. The force applied at each node on the plate is one tenth of the actual force applied.

\section{Finite Element Result}

The FE analysis of the model was set up to examine three different behaviors: initial cracking of the beam, yielding of the steel reinforcement, and the strength limit state of the beam. The application of the loads up to failure was done incrementally. After each load increment was applied, the restart option was used to go to the next step after convergence.

The time at the end of each load step corresponds to the loading applied. For the first load step the time at the end of the load step is 5210 referring to a load of, $\mathrm{P}$, of $5210 \mathrm{lbs}$ applied at the steel plate. The two convergence criteria used for the analysis were Force and Displacement. These criteria were left at the default values up to 5210 lbs. However, when the beam began cracking, convergence for the non-linear analysis was impossible with the default values. The displacements converged, but the forces did not. Therefore, the convergence criterion for force was dropped and the reference value for the Displacement criteria was changed to 5. This value is then multiplied by the tolerance value of 0.05 to produce a criterion of 0.25 during the nonlinear solution for convergence. A small criterion must be used to capture correct response. This criteria was used for the remainder of the analysis. The steps taken to the initial cracking of the beam can be decreased to one load increment to model/capture initial cracking. Once initial cracking of the beam has been passed (5220 lbs), the load increments increased slightly until subsequent cracking of the beam $(14,000 \mathrm{lbs})$. Once the yielding of the reinforcing steel is reached, the load increments must be decreased again. Yielding of the steel occurs at load step 13,350; therefore, the load increment sizes begin decreasing further because displacements are increasing more rapidly. Eventually, the load increment size is decreased to $2 \mathrm{lb}$. to capture the failure of the beam. Failure of the beam occurs when convergence fails, with this very small load increment. The load deformation trace produced by the analysis confirmed the failure load. The result from FE analysis of the model for the three different behaviors: initial cracking of the beam, yielding of the steel reinforcement, and the strength limit state of the beam are shown in Figure 6. 

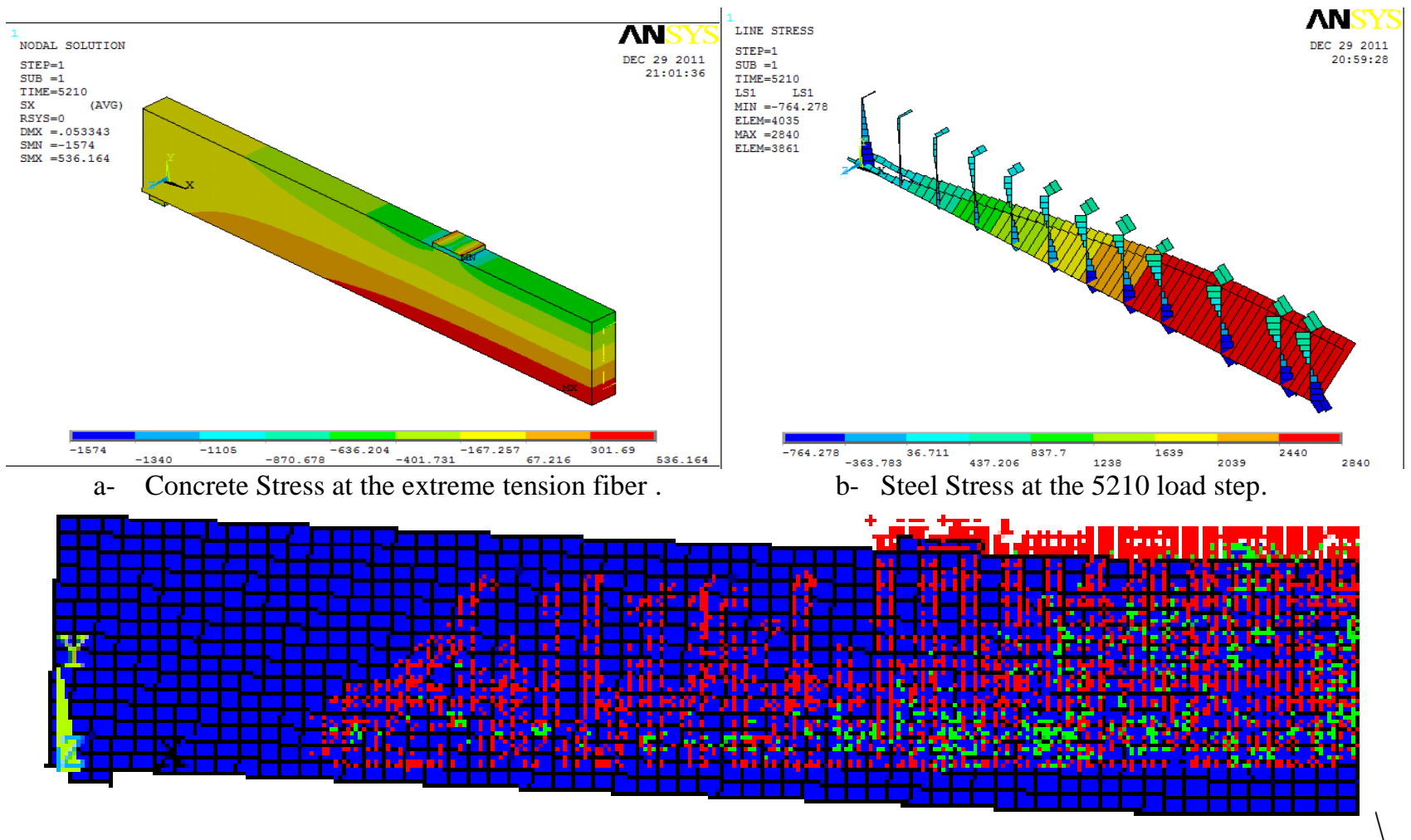

c- Failure of the Concrete Beam.

Fig. 6: a)- Concrete Stress at the extreme tension fiber, b) - Steel Stress at the 5210 load step, c) - Failure of the Concrete Beam.

The analysis of the linear region can be based on the design for flexure given in [9] for a reinforced concrete beam. The comparisons were made in this region to ensure deflections and stresses were consistent with the FE model and the beam before cracking occurred. The results in Table 4 indicate that the FE analysis of the beam prior to cracking is acceptable.

Table 2: Deflections and Stress Comparisons at First Cracking.

\begin{tabular}{|c|c|c|c|c|}
\hline Model & $\begin{array}{c}\text { Extreme } \\
\text { tension fiber } \\
\text { stress (Psi) }\end{array}$ & $\begin{array}{c}\text { Reinforcement steel } \\
\text { stress (psi) }\end{array}$ & $\begin{array}{c}\text { Deflection } \\
\text { (in) }\end{array}$ & Load at first Crack \\
\hline Hand Calculation & 530 & 3024 & 0.0529 & 5118 \\
\hline ANSYS & 536 & 2840 & 0.0534 & 5216 \\
\hline
\end{tabular}

The full nonlinear load-deformation response can be seen in Figure 9. This load-deformation curve fits to the curve from [10]. The response calculated using FEA is plotted upon the experimental response from [10]. The entire load-deformation response of the model produced compares well with the response from [10]. This gave confidence in the use of ANSYS and the model developed. 


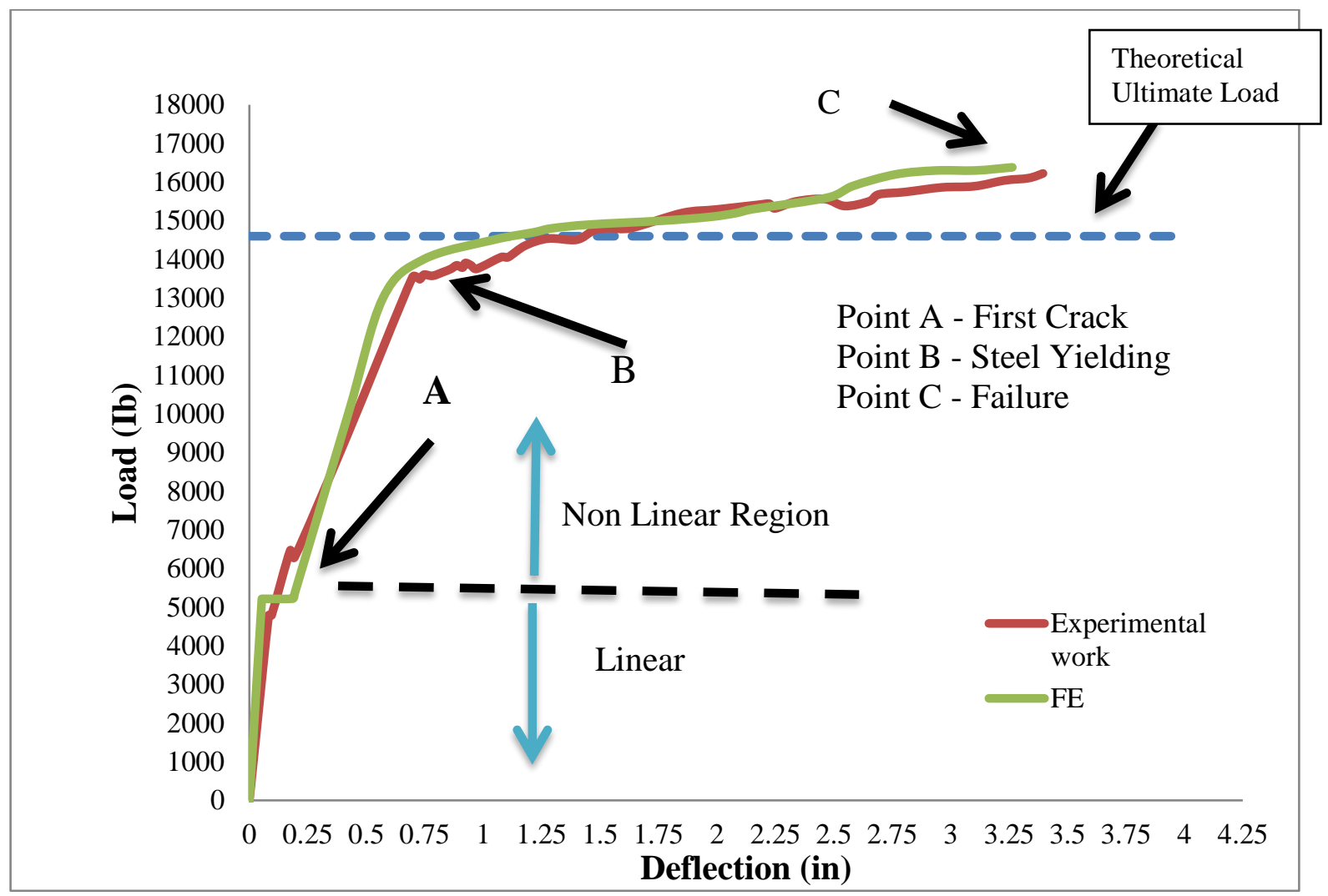

Fig. 9: Comparison of Loads vs. Deflection Curve between FE analysis and result of experimental work by [8].

\section{Conclusions}

In this research work a study of reinforced concrete beams using finite element analysis in order to understand the response of reinforced concrete beams due to transverse loading. The reinforced concrete beam with flexural and shear reinforcement was analyzed to failure and compared to experimental results. A multi-linear isotropic material uses the Von-Misses failure criterion a long with William and Warnke (1974) model to define the failure of the concrete, with using solid65 element, and crushing. Solid45 element was used for steel plates at the supports for the beam. For reinforcement material a linear isotropic and bilinear isotropic material, with a Link8 element was used to model steel reinforcement.

The following conclusions can be stated based on the evaluation of the analyses of the FE model for concrete beam.

(1) Deflections and stresses at the centerline along with initial and progressive cracking of the finite element model compare well to analytical model based on energy method and the experimental data obtained from a reinforced concrete beam.

(2) The failure mechanism of a reinforced concrete beam is modeled quite well using FEA, and the failure load predicted is very close to the failure load measured during experimental testing, it is worth to mention that in such numerical solution a possible error of the analysis may be occurred.

\section{Reference}

[1] ANSYS, Release, 11.0, Documentation for ANSYS, 2007 SAS IP.

[2] K. Willam, T. A. Tanabe, Finite Element Analysis of Reinforced Concrete Structures. American Concrete Institute, Farmington Hills, MI, 2001. 
[3] P. B. Shing, T. A. Tanabe, Modeling of inelastic behavior of RC structures under seismic loads. ASCE Publications, 2001.

[4] M. Kaya, A. Samet Arslan, "Analytical modeling of post-tensioned precast beam-to-column connections," Materials \& Design, vol. 30, no. 9, pp. 3802-3811, 2009.

[5] A. Niroomandi, A. Maheri, Mahmoud R. Maheri, S. S. Mahini, "Seismic performance of ordinary RC frames retrofitted at joint by FRP sheets," Engineering Structures, vol. 32, no. 8, pp. 2326-2336, 2010.

[6] R. Ravi. S, P. Arulraj G., "Finite Element Modeling on behavior of Reinforced Concrete Beam-Column Joints Retrofitted with Carbon Fiber Reinforced Polymer Sheets," International Journal of Civil and Structural Engineering, vol. 1, no 3, 2010.

[7] R. A. Hawileh, M. Naser, W. Zaidan, H. A. Rasheed, "Modeling of insulated CFRP-strengthened reinforced concrete T-beam exposed to fire," Engineering Structures, vol. 31, no. 12, pp. 3072-3079, 2009.

[8] Willam, K. J., and E. P. Warnke. "Constitutive Model for Triaxial Behaviour of Concrete", Seminar on Concrete Structures Subject to Triaxial Stresses." International Association of Bridge and Structural Engineering Conference, Bergamo, Italy. 1974.

[9] J. G. MacGregor, Reinforced concrete: Mechanics and design. 1992.

[10] E. R. Buckhouse, "External Flexural Reinforcement of Existing Reinforced Concrete Beams Using Bolted Steel Channels,” M.S. Thesis, Marquette University, Milwaukee, Wisconsin, 1997. 